\title{
Role of age in acute type A aortic dissection outcome: Report from the International Registry of Acute Aortic Dissection (IRAD)
}

\author{
Santi Trimarchi, MD, ${ }^{a}$ Kim A. Eagle, MD, ${ }^{\mathrm{b}}$ Christoph A. Nienaber, MD,${ }^{\mathrm{c}}$ Vincenzo Rampoldi, MD, ${ }^{\mathrm{a}}$ \\ Frederik H. W. Jonker, MD, ${ }^{\mathrm{d}}$ Carlo De Vincentiis, MD, ${ }^{\mathrm{a}}$ Alessandro Frigiola, MD, ${ }^{\mathrm{a}}$ \\ Lorenzo Menicanti, MD, ${ }^{\mathrm{a}}$ Thomas Tsai, MD, ${ }^{\mathrm{b}}$ Jim Froehlich, MD, ${ }^{\mathrm{b}}$ Arturo Evangelista, MD, \\ Daniel Montgomery, MD, ${ }^{\mathrm{b}}$ Eduardo Bossone, MD,${ }_{\mathrm{f}}$ Jeanna V. Cooper, MS, ${ }^{\mathrm{b}} \mathrm{Jin} \mathrm{Li}, \mathrm{MS},{ }^{\mathrm{b}}$ \\ Michael G. Deeb, MD, ${ }^{\mathrm{b}}$ Gabriel Meinhardt, MD, ${ }^{\mathrm{g}}$ Thoralf M. Sundt, MD, ${ }^{\mathrm{h}}$ and Eric M. Isselbacher, MD, ${ }^{\mathrm{i}}$ on \\ behalf of the International Registry of Acute Aortic Dissection (IRAD) Investigators
}

\begin{abstract}
Objective: The increasing life expectancy of the population will likely be accompanied by a rise in the incidence of acute type A aortic dissection. However, because of an increased risk of cardiac surgery in an elderly population, it is important to define when, if at all, the risks of aortic repair outweigh the risk of death from unoperated type A aortic dissection.
\end{abstract}

Methods: We analyzed 936 patients with type A aortic dissection enrolled in the International Registry of Acute Aortic Dissection from 1996 to 2004. Patients with type A aortic dissection were categorized according to patient age by decade and by surgical versus medical management, and outcomes of both management types were investigated in the different age groups.

Results: The rate of surgical aortic repair decreased progressively with age, whereas surgical mortality significantly increased with age. Age 70 years or more was an independent predictor for mortality $(38.2 \%$ vs $26.0 \% ; P<.0001$, odds ratio 1.73 ). The in-hospital mortality rate was significantly lower after surgical management compared with medical management until the age of 80 years. For patients aged 80 to 90 years, the in-hospital mortality appeared to be lower after surgical management (37.9\% vs $55.2 \% ; P=.188)$; however, this failed to reach clinical significance owing to the limited patient number in this age group.

Conclusions: Although the surgical mortality significantly increased with increased age, surgical management was still associated with significantly lower in-hospital mortality rates compared with medical management until the age of 80 years. Surgery may decrease the in-hospital mortality rate for octogenarians with type A aortic dissection and might be considered in all patients with type A aortic dissection regardless of age. (J Thorac Cardiovasc Surg 2010;140:784-9)

The increasing life expectancy of the population will be accompanied by a rise in the incidence of cardiovascular disease including acute type A aortic dissection (AAD). ${ }^{1}$

The mortality rate of untreated AAD increases $1 \%$ to $2 \%$ every hour after first presentation, and immediate surgical intervention is indicated after diagnosis of AAD. Currently, the in-hospital mortality rate of AAD is $15 \%$ to $30 \%,{ }^{2-6}$ and

From the Policlinico San Donato IRCCS, ${ }^{\text {a }}$ San Donato Milanese, Italy; University of Michigan, ${ }^{\mathrm{b}}$ Ann Arbor, Mich; University of Rostock, ${ }^{\mathrm{c}}$ Rostock, Germany; Yale University, ${ }^{\mathrm{d}}$ New Haven, Conn; Hospital General Universitari Vall d'Hebron, ${ }^{\mathrm{e}}$ Barcelona, Spain; National Research Council, ${ }^{\mathrm{f}}$ Lecce, Italy; Robert-Bosch Krankenhaus, ${ }^{\mathrm{g}}$ Stuttgart, Germany; Mayo Clinic, ${ }^{\text {h }}$ Rochester, Minn; and Massachusetts General Hospital, ${ }^{\mathrm{i}}$ Boston, Mass.

Disclosures: IRAD is supported by grants from the University of Michigan Health System, the Varbedian Fund for Aortic Research, the Mardigian Foundation, and Gore Inc.

Received for publication July 24, 2009; revisions received Oct 1, 2009; accepted for publication Nov 6, 2009; available ahead of print Feb 22, 2010.

Address for reprints: Santi Trimarchi, MD, Policlinico San Donato IRCCS, Cardiovascular Center “E. Malan', University of Milano, Piazza Malan 2, 20097 S. Donato Milanese, Italy (E-mail: santi.trimarchi@unimi.it; santi.trimarchi@grupposandonato.it). $0022-5223 / \$ 36.00$

Copyright (c) 2010 by The American Association for Thoracic Surgery doi: $10.1016 /$ j.jtcvs.2009.11.014 this outcome appears generally unimproved over time. ${ }^{4}$ Increased age has shown to be a strong independent predictor of in-hospital mortality of cardiovascular interventions, ${ }^{7-10}$ including surgical repair of AAD. ${ }^{2,11,12}$ For very elderly patients with AAD, medical management may be an alternative treatment option; therefore, it is important to define at what age, if at all, the risks of aortic repair outweigh the risk of death from medically managed AAD.

The International Registry of Acute Aortic Dissection (IRAD) provides an opportunity to investigate the role of age in AAD outcomes and to determine whether the management type of AAD should depend on the patient's age. We used the registry to evaluate outcome of patients with AAD after surgical and medical management in different age groups and to define individual treatment strategies for elderly patients with AAD.

\section{METHODS}

\section{Patient Selection}

We analyzed all patients with acute AAD enrolled in the International Registry of Acute Aortic Dissection (IRAD) from 1996 to 2004. IRAD is an ongoing international multicenter registry started in 1996 that includes 


\section{Abbreviations and Acronyms \\ $\mathrm{AAD}=$ type $\mathrm{A}$ aortic dissection \\ IRAD $=$ International Registry of Acute Aortic Dissection \\ $\mathrm{OR}=$ odds ratio}

consecutive patients with acute aortic dissection at 24 large referral centers (IRAD centers; Appendix), which rationale has previously been described. ${ }^{13}$ Acute AAD was defined as any dissection that involved the ascending aorta that was presented within 14 days after onset of symptoms. In total, 936 patients with AAD were identified and included for analysis. All patients were categorized according to patient age by decade; surgical versus medical management and outcomes of both management types were investigated in the different age groups.

\section{Data Extraction}

Data were collected on a standard questionnaire form developed by IRAD investigators. Data collection included variables regarding demographics, history, clinical presentation, physical findings, imaging study results, medical and surgical management, in-hospital clinical events, length of stay, and hospital mortality. Completed data forms were submitted to the IRAD coordinating center at the University of Michigan.

\section{Statistical Analysis}

Summary statistics were presented as frequencies and percentages, mean \pm standard deviation, or as a median and interquartile range. Missing data were not defaulted to negative and denominators reflect only actual reported cases. Nominal variables were compared between patients less than 70 years and 70 years of age and older, as well as between medical and surgical groups, using the $\chi^{2}$ test or 2-sided Fisher exact test. Iterative logistic modeling was performed to investigate independent predictors of in-hospital mortality using likelihood ratio tests. Initial modeling implemented elements marginally suggestive of an unadjusted association to in-hospital mortality $(P<.20)$. Variables were reviewed for clinical significance before testing. Diagnostic routines (Hosmer-Lemeshow test for lack of fit, change in deviance and residuals, and leverage indicators) were used for the final model selection. SAS 8.2 (SAS Institute, Inc, Cary, NC) and SPSS 11.5 (SPSS, Inc, Chicago, Ill) were used for the analyses. A $P$ value $<.05$ was considered significant.

\section{RESULTS}

\section{Demographics, Patient History, and Presentation}

The incidence of AAD was higher during the seventh and eighth decades (Figure 1). Of all patients with AAD, 32.2\% $(\mathrm{n}=301)$ were 70 years of age and older. Men constituted $46.8 \%$ of the elderly and $53.2 \%$ of the younger cohort $(P<.0001)$. Histories of hypertension, atherosclerosis, prior aortic aneurysm, diabetes mellitus, and prior cardiac surgery were more frequently present among patients 70 years and older, whereas Marfan syndrome was only seen in the younger cohort (Table 1).

Patients with AAD who were younger than 70 years more frequently had an abrupt onset of pain and pulse deficit than did patients 70 years of age and older; hypotension was more often seen at presentation among the older patient cohort (Table 1).

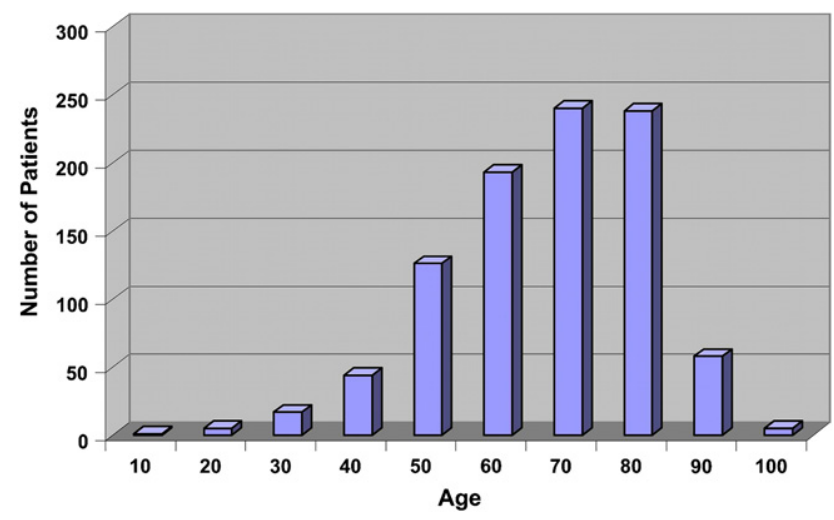

FIGURE 1. Age of patients with AAD in IRAD. Age groups are labeled according to the upper age limit; for example, age group 30 includes patients 20 years of age to 30 years.

\section{In-Hospital Management}

Of all patients with AAD, $82.9 \%$ were managed surgically, $16.6 \%$ were managed medically, and $0.5 \%$ underwent percutaneous stenting or fenestration. Surgery was more frequently adopted in patients younger than 70 years and medical therapy in patients older than 70 years (surgical management in patients aged $<70$ vs $\geq 70: 88.5 \%$ vs $71.1 \% ; P<.0001 ;$ medical management in patients aged $<70$ vs $\geq 70: 10.9 \%$ vs $28.6 \%, P<.0001$ ) (Table 2 ).

In IRAD AAD patients, the reasons listed for medical treatment only were advanced age, intramural hematoma, severe comorbidities, or refusal of surgery by patients, families, or the care team. The rate of surgical aortic repair decreased progressively with age, whereas the rate of medical management increased with age (Table 3, Figure 2). The use of surgical and medical management was equal for octogenarians, and medical treatment was more frequently offered to the 5 patients with AAD who were more than 90 years of age (Figure 2).

\section{In-Hospital Outcomes}

The overall in-hospital mortality was $23.8 \%$ among patients treated surgically versus $59.3 \%$ among patients managed medically $(P<.0001)$. The in-hospital mortality rate for patients managed surgically increased with increased age, whereas the in-hospital mortality rate of patients treated medically remained roughly stable (Table 3 , Figure 3 ). The in-hospital mortality rate was significantly lower after surgical management compared with medical management until the age of 80 (Table 3). For patients aged 80 to 90 years, surgical management showed a trend to decrease the in-hospital mortality rate compared with medical management; however, this difference failed to reach clinical significance $(37.9 \%$ vs $55.2 \% ; P=.188)$. The point estimates for inhospital mortality rates of both management types for patients 90 years of age and older were not reliable owing to the low number of patients in both groups (Table 3). 
TABLE 1. Demographics, patient history, presentation, and signs

\begin{tabular}{|c|c|c|c|}
\hline Variable & $\begin{array}{c}\begin{array}{c}\text { Patients } \\
\text { aged }<70 \text { y }\end{array} \\
\text { No. }(\%)\end{array}$ & $\begin{array}{c}\begin{array}{c}\text { Patients } \\
\text { aged } \geq 70 \mathrm{y}\end{array} \\
\text { No. }(\%)\end{array}$ & \\
\hline Total patients & $635(67.8)$ & $301(32.2)$ & \\
\hline \multicolumn{4}{|l|}{ Demographics } \\
\hline Gender (male) & $166(53.2)$ & $146(46.8)$ & $<.0001$ \\
\hline \multicolumn{4}{|l|}{ Etiology and history } \\
\hline Marfan syndrome & $45(7.3)$ & $0(0)$ & $<.0001$ \\
\hline Hypertension & $410(66.7)$ & $219(75.8)$ & .0055 \\
\hline Atherosclerosis & $119(19.5)$ & $112(38.9)$ & $<.0001$ \\
\hline Prior aortic aneurysm & $62(10.2)$ & $48(16.7)$ & .0054 \\
\hline Prior aortic dissection & $23(3.8)$ & $7(2.4)$ & .30 \\
\hline Diabetes & $15(2.5)$ & $21(7.4)$ & .0006 \\
\hline Prior cardiac surgery & $77(13.0)$ & $66(24.2)$ & $<.0001$ \\
\hline CABG & $30(5.0)$ & $27(9.7)$ & .0084 \\
\hline Cardiac catheterization* & $37(9.3)$ & $38(20.2)$ & .0002 \\
\hline \multicolumn{4}{|l|}{ Clinical presentation and signs } \\
\hline Hypotension or shock & $157(26.2)$ & 85 (31.6) & .10 \\
\hline Abrupt onset of pain & $520(87.3)$ & $217(80.4)$ & .01 \\
\hline Hypotension & $86(14.5)$ & $54(20.3)$ & .03 \\
\hline $\begin{array}{l}\text { Coma/altered } \\
\text { consciousness }\end{array}$ & $82(13.9)$ & $33(11.7)$ & .38 \\
\hline Spinal cord ischemia & $16(2.7)$ & $2(0.7)$ & .07 \\
\hline Any pulse deficit & $176(32.3)$ & $63(23.9)$ & .01 \\
\hline
\end{tabular}

$C A B G$, Coronary artery bypass grafting. *Data regarding prior cardiac catheterization were missing in $38 \%$.

\section{Predictors of In-Hospital Mortality}

Age 70 years or older was an independent predictor for inhospital mortality among patients with AAD (38.2 vs $26.0 \% ; P<.0001$, odds ratio [OR] 1.73 , Table 4). Other significant independent predictors of in-hospital mortality for the cohort included coma and/or cerebrovascular accident (OR, 2.94), preoperative acute renal failure (OR, 2.47), hypotension/shock at presentation (OR, 3.21), abrupt onset of symptoms (OR, 2.11), ischemic peripheral neuropathy (OR, $3.35)$, and prior cardiac surgery (OR, 1.84); a history of hypertension was associated with lower mortality (OR, 0.56).
TABLE 2. In-hospital management and mortality of AAD

\begin{tabular}{|c|c|c|c|}
\hline & $\frac{\begin{array}{c}\text { Patients } \\
\text { aged }<70 \mathrm{y}\end{array}}{\text { No. }(\%)}$ & $\frac{\begin{array}{c}\text { Patients } \\
\text { aged } \geq 70 \mathrm{y}\end{array}}{\text { No. }(\%)}$ & $P$ value \\
\hline Total patients & $635(67.8)$ & $301(32.2)$ & \\
\hline \multicolumn{4}{|l|}{ Definitive management } \\
\hline Surgery & $562(88.5)$ & $214(71.1)$ & $<.0001$ \\
\hline Medical treatment & $69(10.9)$ & $86(28.6)$ & $<.0001$ \\
\hline Percutaneous & $4(0.6)$ & $1(0.3)$ & NA \\
\hline \multicolumn{4}{|l|}{ Initial medicine* } \\
\hline Beta-blocker & $299(51.7)$ & $128(47.4)$ & .24 \\
\hline Nitroprusside & $182(31.9)$ & $67(25.8)$ & .08 \\
\hline Calcium channel blocker & $82(14.6)$ & $35(13.8)$ & .77 \\
\hline Mortality & $165(26.0)$ & $115(38.2)$ & .0001 \\
\hline Surgery mortality & $119(21.2)$ & $66(30.8)$ & .005 \\
\hline Medical mortality & $44(63.8)$ & $48(55.8)$ & .32 \\
\hline
\end{tabular}

$A D D$, Type $\mathrm{A}$ aortic dissection; $\mathrm{NA}$, not available; percutaneous includes percutaneous stenting and fenestration. ${ }^{*}$ Data regarding long-term medicine were missing in $30 \%$.

\section{Proportion of Preoperative Risk Factors Among In- Hospital Deaths in Patients Younger Than 70 Years and 70 Years of Age and Older}

Among preoperative risk factors that usually are associated with higher mortality, such as shock (systolic blood pressure $<80 \mathrm{~mm} \mathrm{Hg}$ ), coma and/or cerebrovascular accident, cardiac tamponade, limb ischemia, acute renal failure, visceral ischemia, myocardial ischemia and/or infarction, history of aortic valve replacement, and prior cardiac surgery, only the last variable was significantly more frequently present among nonsurvivors of 70 years and older compared with nonsurvivors younger than 70 years $(P=.0005$, Table 5$)$.

\section{DISCUSSION}

With the increasing life expectancy of the population, an increased incidence of acute aortic diseases is expected. IRAD confirmed that AAD is more common during the seventh and eighth decades, although the condition is not uncommon during the fifth and sixth decades. Previous studies, as well as reports of IRAD, have shown that

TABLE 3. In-hospital mortality after medical and surgical management for different age groups

\begin{tabular}{|c|c|c|c|c|c|c|c|}
\hline \multirow[b]{2}{*}{$\operatorname{Age}(y)$} & \multicolumn{3}{|c|}{ Management } & \multicolumn{3}{|c|}{ Mortality rate } & \multirow[b]{2}{*}{$P$ value } \\
\hline & Overall & Medical & Surgical & Overall & Medical & Surgical & \\
\hline $0<10$ & $1(100.0)$ & $1(100.0)$ & $0(0.0)$ & $0(0.0)$ & - & - & NA \\
\hline $10<20$ & $5(100.0)$ & $1(20.0)$ & $4(80.0)$ & $2(40.0)$ & $1(100.0)$ & $1(25.0)$ & NA \\
\hline $20<30$ & $17(100.0)$ & $1(5.9)$ & $16(94.1)$ & $5(29.4)$ & $1(100.0)$ & $4(25.0)$ & NA \\
\hline $30<40$ & $44(100.0)$ & $0(0.0)$ & $44(100.0)$ & $9(20.5)$ & - & $9(20.5)$ & NA \\
\hline $40<50$ & $124(98.4)$ & $12(9.5)$ & $112(88.9)$ & $27(21.8)$ & $8(66.7)$ & $20(17.5)$ & $<0.001$ \\
\hline $50<60$ & $192(99.5)$ & $18(9.3)$ & $174(90.2)$ & $44(22.9)$ & $11(61.1)$ & $33(18.9)$ & $<0.001$ \\
\hline $60<70$ & 239 (99.6) & $34(14.2)$ & 205 (85.4) & $72(30.1)$ & $21(61.8)$ & $52(25.2)$ & $<0.001$ \\
\hline $70<80$ & 237 (99.6) & $53(22.3)$ & $184(77.3)$ & $83(35.0)$ & $29(54.7)$ & 55 (29.7) & 0.001 \\
\hline $80<90$ & $58(100.0)$ & $29(50.0)$ & $29(50.0)$ & $27(46.6)$ & $16(55.2)$ & $11(37.9)$ & 0.188 \\
\hline $90<100$ & $5(100.0)$ & $4(80.0)$ & $1(20.0)$ & $4(80.0)$ & $3(75.0)$ & $1(100.0)$ & NA \\
\hline
\end{tabular}

NA, Not available. 


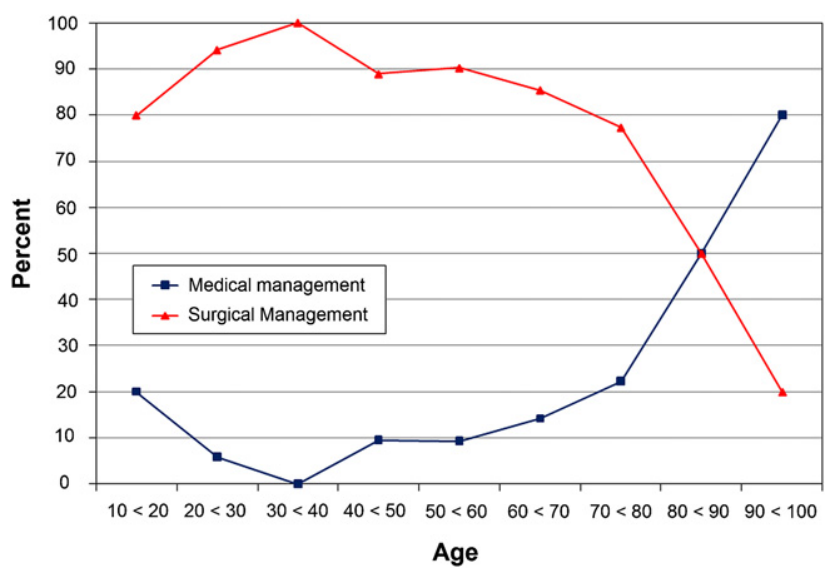

FIGURE 2. Management of AAD in different age groups.

increased age is associated with increased short- and longterm mortality rates after cardiovascular interventions, ${ }^{7-10}$ including AAD surgery. ${ }^{11,12,14}$ In this report, we confirmed that increased age is an independent predictor of in-hospital mortality, and we further investigated outcomes of patients with AAD after surgical and medical management in different age groups.

Ascending aortic repair is the standard of care for managing $\mathrm{AAD}$, although this is still associated with important mortality rates. Whether or not to operate on very elderly patients with AAD has been debated in the literature. ${ }^{15-21}$ Some have suggested that surgical repair of AAD can be performed in elderly patients with acceptable results, ${ }^{15,16,18-20}$ whereas others advocate a less aggressive approach or denial of surgical treatment for patients above 80 years, where some reports cite surgical mortality rates of up to $83 \%{ }^{17,21}$ When elderly patients with AAD treated surgically do survive the hospitalization, their long-term survival is often satisfactory. ${ }^{16,18-21}$ Most of these studies do not compare the surgical outcome of AAD treated with the alternative treatment, medical management. In the present study, we observed that, although the surgical mortality increased with increased age, surgical management was still associated with significantly lower in-hospital mortality rates than was medical management for AAD patients until the age of 80 years; in addition, it appeared to decrease the in-hospital mortality rate for octogenarians with AAD (38\% vs $55 \%)$.

In IRAD AAD patients, other important preoperative risk factors for in-hospital mortality, besides an increased age, were an abrupt onset of symptoms, hypotension and shock, coma and/or cerebrovascular accident, preoperative acute renal failure, and prior cardiac surgery, which have been reported previously. ${ }^{22}$ Surprisingly, among nonsurvivors 70 years of age and older, of the most common preoperative risk factors for mortality, only prior cardiac surgery was more frequent compared with nonsurvivors younger than 70 years. This risk factor was more frequently present preoperatively among the elderly patients with AAD as well.

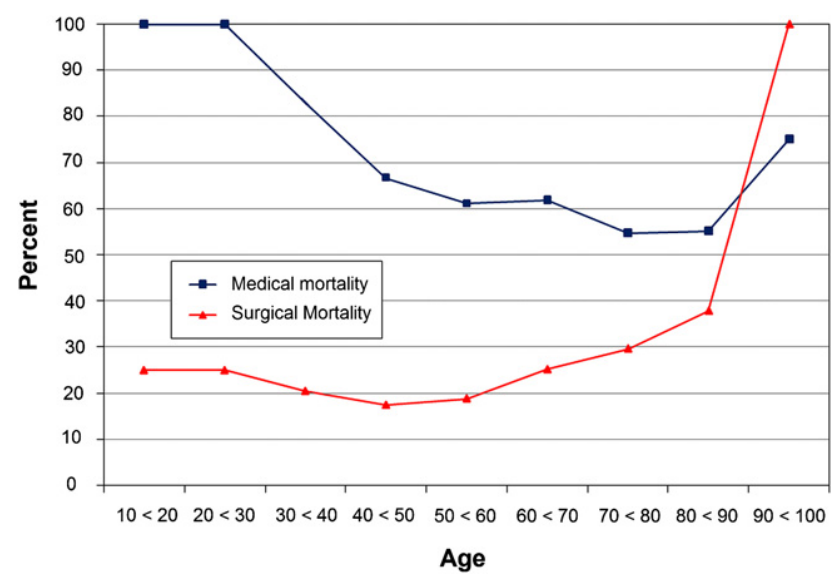

FIGURE 3. In-hospital mortality of AAD categorized by age and management type.

In recent years, improving cardiopulmonary bypass technology allows for safer procedures with a reduced morbidity and mortality in older patients. ${ }^{23,24}$ Although we observed that advanced age is not a reason per se to refuse surgery, institutions or individual physicians may approach this issue differently. The decision whether or not to offer surgical repair to a very elderly patient with AAD should be based on individual patient characteristics and the expertise of the operator or institution.

A surprising finding was that, in contrast to the surgical mortality, medical mortality did not increase with increased age. Perhaps medical management was only offered to younger patients with $\mathrm{AAD}$ if more significant comorbidities or complications were present that prohibited surgery. Additionally, younger patients who were not managed surgically may have died before surgical repair could have been offered. IRAD is an observational registry and therefore a selection bias may have been present.

For surviving patients, it is important to consider subsequent survival and quality of life. Generally, advanced age is associated with considerable neurologic complications

TABLE 4. Independent predictors of in-hospital mortality among patients with AAD

\begin{tabular}{lccrr}
\hline \multicolumn{1}{c}{ Variables in the model } & OR & \multicolumn{2}{c}{$\mathbf{9 5} \%$ CI } & $\boldsymbol{P}$ value \\
\hline Age $\geq 70$ y & 1.728 & 1.060 & 2.816 & .0281 \\
History of hypertension & 0.556 & 0.339 & 0.912 & .0201 \\
Prior cardiac surgery & 1.841 & 1.013 & 3.347 & .0452 \\
Abrupt onset & 2.107 & 1.004 & 4.425 & .0489 \\
Hypotension + shock & 3.211 & 1.994 & 5.170 & $<.0001$ \\
Coma and/or CVA & 2.937 & 1.410 & 6.119 & .0040 \\
Preoperative ARF & 2.468 & 1.133 & 5.379 & .0230 \\
$\begin{array}{l}\text { Ischemic peripheral } \\
\quad \text { neuropathy }\end{array}$ & 3.349 & 1.121 & 10.003 & .0304 \\
$\begin{array}{l}\text { Pleural effusion on } \\
\quad \text { chest x-ray films }\end{array}$ & 1.706 & 0.950 & 3.063 & .0736 \\
\hline
\end{tabular}

$O R$, Odds ratio; $C I$, confidence interval; $C V A$, cerebrovascular accident; $A R F$, acute renal failure. 
TABLE 5. Proportion of preoperative risk factors among in-hospital deaths $<70$ years and $\geq 70$ years

\begin{tabular}{lccc}
\hline \multicolumn{1}{c}{ Variable } & $\begin{array}{c}\text { Patients } \\
\text { aged }<70 \text { y }\end{array}$ & $\begin{array}{c}\text { Patients } \\
\text { aged } \geq \mathbf{7 0} \mathbf{y}\end{array}$ & $\boldsymbol{P}$ value \\
\hline Shock & $47(30.3)$ & $29(27.6)$ & .64 \\
Coma and/or CVA & $26(18.3)$ & $10(10.9)$ & .12 \\
Preoperative ARF & $21(13.7)$ & $11(10.9)$ & .51 \\
Preoperative visceral ischemia & $7(4.6)$ & $8(7.8)$ & .28 \\
Preoperative limb ischemia & $30(19.5)$ & $13(13.1)$ & .19 \\
Preoperative cardiac tamponade & $16(10.1)$ & $9(8.1)$ & .57 \\
ECG with ischemic signs* & $15(11.0)$ & $9(8.9)$ & .61 \\
History of AVR & $11(7.1)$ & $5(4.8)$ & .43 \\
Prior cardiac surgery & $22(14.5)$ & $34(32.7)$ & .0005 \\
\hline
\end{tabular}

Shock, Systolic blood pressure $<80 \mathrm{~mm} \mathrm{Hg} ; C V A$, cerebrovascular accident; $A R F$, acute renal failure; $E C G$, electrocardiogram; $A V R$, aortic valve repair. *Ischemic signs include myocardial infarction and/or new Q-wave or ST elevation.

after management of AAD. ${ }^{11,15}$ Elderly patients may become completely bedridden and dependent on the care of family or a nursing home after successful surgical repair of AAD. Recently, Hata and associates ${ }^{15}$ underlined the impact of postoperative complications in octogenarians with AAD, such as stroke, depression, dementia, and/or bedridden status, on their families. ${ }^{15}$ Several families who had to take responsibility for the patients who survived the operation voiced their complaints and even refused to pay for the treatment. Further study of this aspect of care and outcomes is sorely needed.

The findings of the present study should be viewed in the light of its limitations. Data were collected retrospectively and subject to incomplete or missing reporting of events. Most IRAD centers were tertiary referral sites that have significant expertise and experience in the surgical treatment of patients with acute aortic dissection, thus limiting the applicability to centers that lack such capability. ${ }^{25}$ In addition, because the treatment allocation was not random, many factors besides those captured in our study may have contributed to the choice of treatment modality, and a selection bias may have been present. Finally, long-term outcomes were not addressed in this study.

\section{CONCLUSION}

Although the surgical mortality significantly increased with increased age, surgical management was still associated with significantly lower in-hospital mortality rates compared with medical management until the age of 80 years, and it tended to decrease the in-hospital mortality rate for octogenarians with AAD. Therefore, surgery is still recommended for patients with AAD between 70 and 80 years and appears to be beneficial for octogenarians with AAD.

\section{References}

1. Olsson C, Thelin S, Stahle E, Ekbom A, Granath F. Thoracic aortic aneurysm and dissection: increasing prevalence and improved outcomes reported in a nationwide population-based study of more than 14,000 cases from 1987 to 2002. Circulation. 2006;114:2611-8.

2. Ehrlich MP, Ergin MA, McCullough JN, Lansman SL, Galla JD, Bodian CA, et al. Results of immediate surgical treatment of all acute type A dissections. Circulation. 2000;102(19 Suppl. 3):III248-52.
3. Trimarchi S, Nienaber CA, Rampoldi V, Myrmel T, Suzuki T, Mehta RH, et al. Contemporary results of surgery in acute type A aortic dissection: the International Registry of Acute Aortic Dissection experience. J Thorac Cardiovasc Surg. 2005;129:112-22.

4. Narayan P, Rogers CA, Davies I, Angelini GD, Bryan AJ. Type A aortic dissection: has surgical outcome improved with time? J Thorac Cardiovasc Surg. 2008; 136:1172-7.

5. Bachet J, Goudot B, Dreyfus GD, Brodaty D, Dubois C, Delentdecker P, et al. Surgery for acute type A aortic dissection: the Hôpital Foch experience (19771998). Ann Thorac Surg. 1999;67:2006-9.

6. David TE, Armstrong S, Ivanov J, Barnard S. Surgery for acute type A aortic dissection. Ann Thorac Surg. 1999;67:1999-2001.

7. Rich MW, Bosner MS, Chung MK, Shen J, McKenzie JP. Is age an independent predictor of early and late mortality in patients with acute myocardial infarction? Am J Med. 1992;92:7-13.

8. Maggioni AP, Maseri A, Fresco C, Franzosi MG, Mauri F, Santoro E, et al. Age-related increase in mortality among patients with first myocardial infarctions treated with thrombolysis. The Investigators of the Gruppo Italiano per lo Studio della Sopravvivenza nell'Infarto Miocardico (GISSI-2). N Engl J Med. 1993;329:1442-8.

9. Tsai TP, Matloff JM, Chaux A, Kass RM, Lee ME, Czer LS, et al. Combined valve and coronary artery bypass procedures in septuagenarians and octogenarians: results in 120 patients. Ann Thorac Surg. 1986;42:681-4.

10. Blakeman BM, Pifarré R, Sullivan HJ, Montoya A, Bakhos M, Grieco JG, et al. Aortic valve replacement in patients 75 years old and older. Ann Thorac Surg. 1987;44:637-9.

11. Mehta RH, O'Gara PT, Bossone E, Nienaber CA, Myrmel T, Cooper JV, et al. Acute type A aortic dissection in the elderly: clinical characteristics, management, and outcomes in the current era. $J$ Am Coll Cardiol. 2002;40:685-92.

12. Tan ME, Morshuis WJ, Dossche KM, Kelder JC, Waanders FG, Schepens MA. Long-term results after 27 years of surgical treatment of acute type a aortic dissection. Ann Thorac Surg. 2005;80:523-9.

13. Hagan PG, Nienaber CA, Isselbacher EM, Bruckman D, Karavite DJ, Russman PL, et al. The International Registry of Acute Aortic Dissection (IRAD): new insights into an old disease. JAMA. 2000;283:897-903.

14. Tsai TT, Evangelista A, Nienaber CA, Trimarchi S, Sechtem U, Fattori R, et al. Long-term survival in patients presenting with type A acute aortic dissection: insights from the International Registry of Acute Aortic Dissection (IRAD). Circulation. 2006;114(1 Suppl):I350-6.

15. Hata M, Sezai A, Niino T, Yoda M, Unosawa S, Furukawa N, et al. Should emergency surgical intervention be performed for an octogenarian with type A acute aortic dissection? J Thorac Cardiovasc Surg. 2008;135:1042-6.

16. Kawahito K, Adachi H, Yamaguchi A, Ino T. Early and late surgical outcomes of acute type A aortic dissection in patients aged 75 years and older. Ann Thorac Surg. 2000;70:1455-9.

17. Neri E, Toscano T, Massetti M, Capannini G, Carone E, Tucci E, et al. Operation for acute type A aortic dissection in octogenarians: is it justified? J Thorac Cardiovasc Surg. 2001;121:259-67.

18. Caus T, Frapier JM, Giorgi R, Aymard T, Riberi A, Albat B, et al. Clinical outcome after repair of acute type A dissection in patients over 70 years-old. Eur $J$ Cardiothorac Surg. 2002;22:211-7.

19. Chiappini B, Tan ME, Morshuis W, Kelder H, Dossche K, Schepens M. Surgery for acute type A aortic dissection: is advanced age a contraindication? Ann Thorac Surg. 2004;78:585-90.

20. Santini F, Montalbano G, Messina A, D’Onofrio A, Casali G, Viscardi F, et al. Survival and quality of life after repair of acute type A aortic dissection in patients aged 75 years and older justify intervention. Eur J Cardiothorac Surg. 2006;29:386-91.

21. Piccardo A, Regesta T, Pansini S, Concistre G, Dell'Aquila A, Scarano F, et al. Should octogenarians be denied access to surgery for acute type A aortic dissection? J Cardiovasc Surg (Torino). 2009;50:205-12.

22. Rampoldi V, Trimarchi S, Eagle KA, Nienaber CA, Oh JK, Bossone E, et al. Simple risk models to predict surgical mortality in acute type A aortic dissection: the International Registry of Acute Aortic Dissection score. Ann Thorac Surg. 2007;83:55-61.

23. Bacchetta MD, Ko W, Girardi LN, Mack CA, Krieger KH, Isom OW, et al. Outcomes of cardiac surgery in nonagenarians: a 10-year experience. Ann Thorac Surg. 2003;75:1215-20.

24. Ullery BW, Peterson JC, Milla F, Wells MT, Briggs W, Girardi LN, et al. Cardiac surgery in select nonagenarians: should we or shouldn't we? Ann Thorac Surg. 2008;85:854-60.

25. Birkmeyer JD, Stukel TA, Siewers AE, Goodney PP, Wennberg DE, Lucas FL. Surgeon volume and operative mortality in the United States. $N$ Engl J Med. 2003;349:2117-27. 


\section{Appendix}

\section{IRAD Co-Principal Investigators}

Kim A. Eagle, MD, University of Michigan, Ann Arbor, Michigan; Eric M. Isselbacher, MD, Massachusetts General Hospital, Boston, Massachusetts; Christoph A. Nienaber, MD, University of Rostock, Rostock, Germany.

\section{IRAD Co-Investigators}

Eduardo Bossone, MD, National Research Council, Lecce, Italy; Alan Braverman, MD, Washington University School of Medicine, St Louis, Missouri; Stefanos Demertzis, MD, Cardiocentro Ticino, Lugano, Switzerland; Giuseppe DiBenedetto, MD, San Giovanni e Ruggi, Salerno, Italy; Mark Ehrlich, MD, University of Vienna, Vienna, Austria; Arturo Evangelista, MD, Hospital General Universitari Vall d'Hebron, Barcelona, Spain; Rossella Fattori, MD, University Hospital S. Orsola, Bologna, Italy; James Froehlich, MD, and Thomas Tsai, MD, University of Michigan, Ann Arbor, Michigan; Dan Gilon, MD, Hadassah University Hospital, Jerusalem, Israel; Alan Hirsch, MD, and Kevin Harris, MD, Minneapolis Heart Institute, Minneapolis, Minnesota; G. Chad Hughes, MD,
Duke University, Durham, North Carolina; Stuart Hutchison, MD, St Michael's Hospital, Toronto, Ontario, Canada; James L. Januzzi, MD, Massachusetts General Hospital, Boston, Massachusetts; Alfredo Llovet, MD, Hospital Universitario 12 de Octubre, Madrid, Spain; Truls Myrmel, MD, Troms $\varnothing$ University Hospital, Troms $\varnothing$, Norway; Peter Oberwalder, MD, Medical School Graz, Graz, Austria; Patrick O'Gara, MD, and Joshua Beckman, MD, Brigham and Women's Hospital, Boston, Massachusetts; Jae K. Oh, MD, Mayo Clinic, Rochester, Minnesota; Linda A. Pape, MD, University of Massachusetts Hospital, Worcester, Massachusetts; Reed Pyeritz, MD, University of Pennsylvania School of Medicine, Philadelphia, Pennsylvania; Udo Sechtem, MD, and Gabriel Meinhardt, MD, Robert-Bosch Krankenhaus, Stuttgart, Germany; P. Gabriel Steg, MD, Hôpital Bichat, Paris, France; Toru Suzuki, MD, University of Tokyo, Tokyo, Japan; Santi Trimarchi, MD, IRCCS Policlinico San Donato, San Donato, Italy.

\section{Data Management and Biostatistical Support}

Jeanna V. Cooper, MS, Dean E. Smith, PhD, and Elise Woznicki, University of Michigan, Ann Arbor, Michigan. 